\title{
Lean Six Sigma Implementation in the Food Sector: Nexus between Readiness-Critical Success Factors
}

\author{
Sarina Abdul Halim-Lim,, ${ }^{*}$ Nurul Najihah Azalanzazllay¹, Anjar Priyono ${ }^{2}$, Guven Gurkan Inan ${ }^{3}$, Muhammad Iqbal Hussain ${ }^{4}$ \\ ${ }^{1}$ Department of Food Technology, Faculty of Food Science and Technology, Universiti Putra Malaysia, 43400, Malaysia \\ ${ }^{2}$ Department of Management, Universitas Islam Indonesia, Yogyakarta, 55000, Indonesia \\ ${ }^{3}$ Industrial Engineering Department Samsun University, Samsun, 55020, Turkey \\ ${ }^{4}$ Faculty of Mechanical Engineering Technology, Universiti Malaysia, Perlis, 02400, Malaysia
}

\begin{tabular}{l} 
A R T I C L E I N F O \\
\hline Article history: \\
Received: 15 July, 2021 \\
Accepted: 24 October, 202 \\
Online: 09 November, 2021 \\
\hline Keywords: \\
Lean Six Sigma \\
LSS Readiness \\
Critical Success Factors \\
Change Management \\
Food sector
\end{tabular}

\section{Introduction}

A strategic business plan is required in the food sector to minimize the process errors that would impact the product quality. This study which, is an extension of work initially presented in the 2020 IEEE International Conference on Industrial Engineering and Engineering Management (IEEM), addresses Lean Six Sigma (LSS) application as the approach. Recently, there was an increase in quality and lower-cost products demand. The food business experienced challenges due to high customer

*Corresponding Author: Sarina Abdul Halim-Lim, sarinalim@upm.edu.my www.astesj.com

https://dx.doi.org/10.25046/aj060603

\begin{abstract}
A B S T R A C T
Lean Six Sigma (LSS) is a renowned approach for boosting operational excellence and competitive advantage through integrated core objectives of value creation and variation reduction. Despite its proven benefits in many leading companies, LSS implementation in the food sector is still behind compared with other sectors. LSS implementation is costly, and most businesses have failed due to a lack of preparation and an unsupportive organizational culture. Therefore, there is a need to identify LSS readiness factors that suit the food sector to minimize the risk of implementation failure in the industry. The current study concentrates on the LSS pre-implementation phase to determine the competency criteria to adopt LSS customized for the food business. This study will explore the LSS readiness criteria during the pre-implementation stage and critical success factors (CSFs) during the implementation stage in the food sector through Lewin's Change Theory. Twelve food sector employees who were associated with quality management activities were interviewed using a semistructured approach. The interview was recorded, transcribed and the transcription was analyzed using content analysis. The results showed six readiness themes in the food manufacturing sector with twenty-nine LSS readiness attributes, while seventeen factors out of thirty-one CSFs for the LSS at the implementation stage. The identified readiness factors are management commitment and leadership (ten attributes), organizational culture (nine attributes), employee involvement (six attributes), process management (four attributes), project management (four attributes) and external factors (three attributes). Through Pareto analysis, the most prioritized CSFs are from top management and leadership and employee involvement themes, with the training program being identified as the most important LSS CSFs (85\%). This study will serve as a foundation for a benchmarking tool for managers to improve the effectiveness of an LSS implementation in the food sector.
\end{abstract}

expectations, strict food standards, and a competitive market [1]. Furthermore, the food businesses have been combating waste that can occur at any point in the supply chain [2]. But waste elimination requires a structured way of thinking, where new manufacturing initiatives should be considered a valuable innovation for the food businesses. Since 2000, the model for integrating Lean and Six Sigma has been sought by the organization globally to improve process performance, maximize profit and minimize operating costs [3]. Lean has a role to reduce non-value-added activities, which is also considered waste in the 
customer's eyes. Whilst Six Sigma is viewed as a problem-solving methodology focusing on making a process effective by reducing process variations [4]. The hybrid of LSS depicted the mixture of best values of these two effective approaches, enabling both variations and waste reduction across the process [2, 3]. In [4], the author confirmed the prominent advantage of LSS projects in this sector mostly is cost saving. This is what drives and motivates quality executives in the food sector to continue their CI efforts, however, there is another motivation such as the need to abide by the laws and regulations. By reducing overfilling confectionary cream that can be expensive [2], LSS enabled food companies not to distribute underweight food products which can cause them to be penalized. LSS activities also encourage circular economy activities by decreasing waste of overfilling cream [5].

Studies have highlighted that the food business has been slower to adopt the LSS mindset and has remained passive compared to other industries [4] and [6]. The reason is that the cost of products is relatively low compared to the cost structure of the business [7], prioritization on the strict regulations that characterize the food sector [8], the nature of the food sector being conservative towards change.

The perceived management difficulties that the businesses in this sector encounters, for instance resistance to change, may be mitigated through LSS preparedness evaluation outlined by organizational change theory [9]. Resistance to the new effort such as LSS, occurred at various levels within an organization. It considered as a significant issue that could result in the failure of LSS implementation [1], [10] and [11]. Thus, the importance of conducting an assessment on the state of LSS readiness prior the implementation need to be highlighted, because preparedness is one of the LSS implementation success factor by [11]. It also will facilitate the effort to integrate LSS with management innovation such as digital technologies [12]. The pre-implementation stage receives insufficient attention compared to the LSS implementation phase elements, such as crucial success factors (CSFs) and barriers.

Thus, this paper aims to investigate the factors that contribute to LSS preparedness customized to the food context. Variables contributing to the preparedness of LSS and their impact on food sector readiness for LSS implementation must be determined to achieve this research aim.

\section{Literature Review}

\subsection{Lewin's change theory}

Readiness study was pioneered by [13] to technological adoption, in which he established that the term is semantically contrary to the resistance to change. [14] associated readiness for a practice that promotes organizational transformation by minimizing inhibitors of success or uncovering the important points to improve the success of the change. Based on Lewin's theory of change model, it is appropriate to explore the factors contributing to unfreezing and freezing phases to drive any kind of change [15]. Unfreezing refers to accepting the need to make the change and preparing the people ready for the change [15]. By adopting the theory, this study intends to understand two phases of the theory which are the unfreezing, followed by the change phase. in the context of LSS as depicted in the research framework in Figure 1. Several studies have identified the importance of readiness outside of the implementation process and encouraged the longevity of the LSS system [10]. Due to the large venture capital and continuous commitments involved with the adoption of LSS, the company should tactically plan to avoid misspending on CI activities [6] and [16]. Furthermore, the understudied LSS issue especially reluctance towards change, high turnover and complacency of current process performance, are highly involved in the two phases of Lewin's change theory.

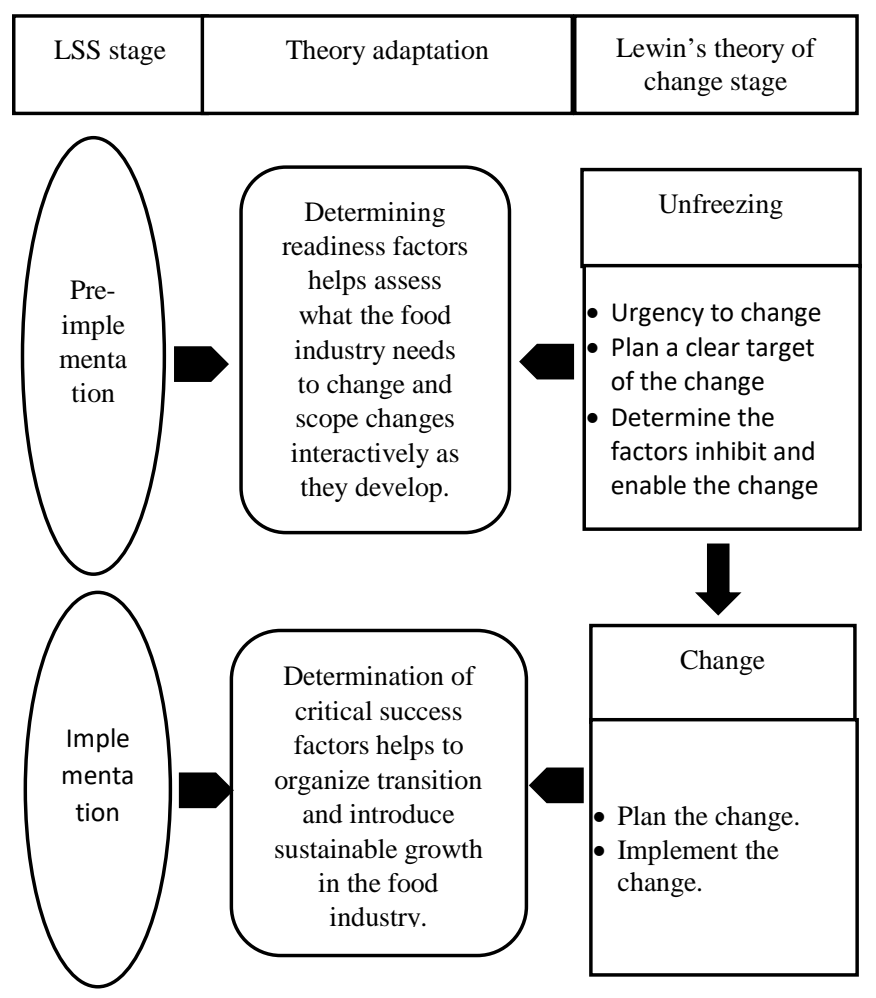

Figure 1: Research framework

\section{Methodology}

Based on the current body of knowledge, there is no research addressing the preparedness of LSS in the context of the food business. This study is primarily an inductive qualitative investigation based on semi-structured interviews comprising practitioners from twelve different food firms familiar with LSS. The inductive approach used in this study appreciates the insights and views of the interviewees as data [17]. This study is filling the gap of knowledge on LSS preparedness in the food business, necessitating a qualitative semi-structured interview rather than a quantitative technique commonly employed in readiness studies in other industries [3]. The research process was guided by the iterative qualitative data analysis model by [18], which comprises data collection, data reduction, data coding and analysis and conclusion, contribution, limitation and future research agenda. 


\subsection{Sampling}

This study applies purposive sampling to choose a suitable sample using the criterion technique. Respondents involving food practitioners that are familiar with LSS and involved in CI projects [19] as depicted in Table 1. The size of a food business can have a causal relationship to LSS implementation effectiveness [6] and [20]. Hence, one of this study's sampling criteria is the experts working in a big company [6]. The interview guideline was created to not only to minimize bias but direct the interview sessions. Then, a pilot interview was carried with three respondents, which was shown by [21]. The interview is inductive in nature, maintaining an adaptive approach to give the chance for probing the questions based on the answers given.

Table 1: Details of the experts

\begin{tabular}{|c|c|c|c|c|}
\hline $\begin{array}{r}\text { Respond } \\
\text { ents }\end{array}$ & $\begin{array}{l}\text { Current } \\
\text { industry }\end{array}$ & Position & $\begin{array}{l}\text { Experien } \\
\text { ce in the } \\
\text { food } \\
\text { sector } \\
\text { (year) }\end{array}$ & Role in LSS \\
\hline E1 & $\begin{array}{l}\text { Cooking } \\
\text { oil }\end{array}$ & $\begin{array}{l}\text { Operational } \\
\text { Excellence } \\
\text { Manager }\end{array}$ & 9 & LSS Black Belt \\
\hline E2 & Dairy & $\begin{array}{l}\text { Production } \\
\text { Manager }\end{array}$ & 14 & $\begin{array}{l}\text { SS Green Belt } \\
\text { Lean Black Belt }\end{array}$ \\
\hline E3 & Dairy & $\begin{array}{l}\text { Process } \\
\text { Engineer }\end{array}$ & 7 & $\begin{array}{l}\text { LSS Green } \\
\text { Belt }\end{array}$ \\
\hline E4 & Fats & $\begin{array}{l}\text { Assistant } \\
\text { Manager } \\
\text { Quality }\end{array}$ & 9 & LSS Green Belt \\
\hline E5 & Beverages & $\begin{array}{l}\text { Production } \\
\text { Engineer }\end{array}$ & 7 & LSS Green Belt \\
\hline E6 & Butter & $\begin{array}{l}\text { Continuous } \\
\text { Improvement } \\
\text { Manager }\end{array}$ & 1 & LSS Black Belt \\
\hline E7 & Dairy & $\begin{array}{l}\text { Operation } \\
\text { Manager }\end{array}$ & 15 & $\begin{array}{l}\text { LSS } \\
\text { Black Belt }\end{array}$ \\
\hline E8 & Dairy & $\begin{array}{l}\text { Operation } \\
\text { Manager }\end{array}$ & 15 & $\begin{array}{l}\text { LSS } \\
\text { Black Belts }\end{array}$ \\
\hline E9 & Beverages & $\begin{array}{l}\text { Quality } \\
\text { Assurance } \\
\text { Executive }\end{array}$ & 2 & $\begin{array}{l}\text { Certified Quality } \\
\text { Engineer }\end{array}$ \\
\hline E10 & $\begin{array}{l}\text { Confection } \\
\text { ary }\end{array}$ & $\begin{array}{l}\text { Value Stream } \\
\text { Manager }\end{array}$ & 13 & LSS Green Belt \\
\hline E11 & Oils & $\begin{array}{l}\text { Supply Chain } \\
\text { Manager }\end{array}$ & 9 & LSS Green Belt \\
\hline E12 & $\begin{array}{l}\text { Meat and } \\
\text { poultry }\end{array}$ & $\begin{array}{l}\text { Quality } \\
\text { Assurance } \\
\text { Manager }\end{array}$ & 10 years & $\begin{array}{l}\text { Six Sigma } \\
\text { Green Belt }\end{array}$ \\
\hline
\end{tabular}

\subsection{Data collection}

There are two steps of data collection involved in this study. The first step is three pilot interview sessions were conducted as outlined by [21] in the literature, followed by the twelve semistructured interviews using revised interview protocol. The interviews lasted ranges 60 to 180 minutes and were conducted face-to-face in the English language. Interviews were performed using a checklist, with notes and commentaries inserted throughout the session. With the participants' permission, the researcher recorded the interview sessions and comprehensive notes taken during the sessions. In grounded theory, the sample size cannot be established in advance because it is dependent on the emerging theoretical categories [22]. The theory becomes evident when gathering new data no longer sparks new theoretical insights of the theoretical categories [8]. The twelve interviews with practitioners resulted in data saturation due to data overlap and no new insight materials being offered after the ninth interview, exhibiting the aspects of data saturation [21] and [22]. Despite reaching data saturation with the tenth respondent, the researcher conducted two additional interview sessions to confirm that no new information emerged, as shown in Figure 2.

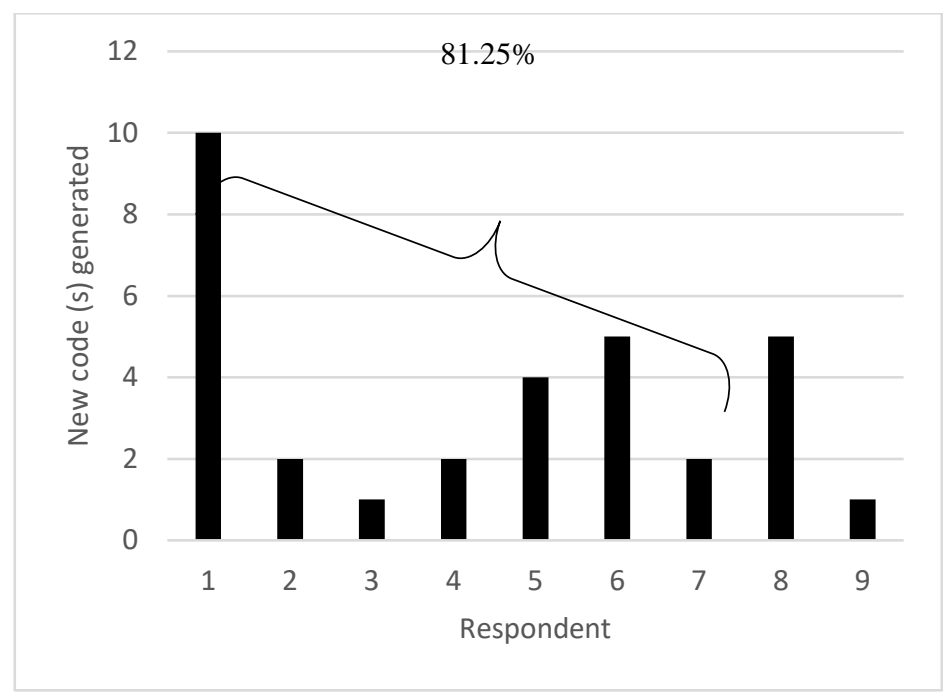

Figure 2: New LSS readiness codes generated at each interview

\subsection{Data coding and analysis}

Shortly after the interview, the interview sessions were familiarized and verbatim transcribed before the process of data reduction. The data was analyzed following the abductive approach, which combined interpretative content analysis and deductive themes identification [18]. The data was transcribed using software QSR Nvivo 12, and a field note was used to complement the transcription. The transcripts of the interviews were familiarized during data reduction, and the coding procedure was carried out to identify appropriate data pertinent that appropriate with the topic, as described by [18].

There are three fundamental coding modes in grounded theory: open, axial, and selective [22]. In open coding, the transcribed interviews are accurately conceptualized into appropriate readiness themes. The researchers were able to infer new meanings from the data collected using inductive coding, while the research objectives guided the emergent coding. During the axial coding phase, the content from the open coding themes was then assessed to develop linkages between the themes. The themes that resulted from the axial coding describe the emergent pattern in the LSS implementation and organizational readiness to change theory. Selective coding was conducted as the final step, where the purpose is to identify the core themes of the LSS readiness framework. 
Comprehensive data analysis and explanation were performed to verify and clarify previously developed logical findings. The four components of [23] were applied to this investigation to guarantee the data presented was reliable. The causal map depicting the causal relation of readiness factors is developed based on inductive data analysis [24], [25] and [26]. The map depicts connected links by arrows, that showed the reviewers' inferred causality [25]. Descriptive analysis through Pareto analysis was conducted to identify the most important LSS CSFs.

\section{Results}

The determination of the key factors of the LSS preimplementation stage will be conducted with consideration at both the 'unfreezing' and 'freezing' stages outlined by several readiness studies [27]. The findings revealed CSFs that could help coordinate LSS implementation in the context of the food sector during transitional periods [4].

\subsection{Readiness factors in the food sector}

Through the qualitative evaluation of employees in the food sector that has been practicing LSS, this study gathered a lot of data about the influence of LSS readiness criteria. When 29 readiness factors were identified through the interview process, the results of the interviews were described in terms of the highest number of mentioned readiness factors by those who took part in interviews.

The result shows that management support has topped all the identified LSS readiness factors. The respondents stated leadership and management are both have a critical role in LSS deployment. Top management is highly suggested to communicate their vision on LSS adoption and set realistic targets for the LSS program in the company. In the food sector, effective communication by the top management is one of the critical ingredients in encouraging the employees' involvement in the LSS related activities under their strict quality assurance programme.

The result shows that, although the regulations and industry standards outline the most quality programmes in the food sector, the top management has a critical role in developing the urgency towards the LSS adoption at the organizational level. According to respondent E7, senior management should keep a consistent cadence when encouraging the industry to adopt LSS. Top management support can be viewed by their overall knowledge on the "why" and "how" LSS implementation can contribute to their operational performance and company's bottom line and subsequently oversee towards business excellence.

The second critical readiness factor is financial support allocated for the program's implementation and its continuation in the company. Financial investment is the most important type of support from upper management, as it has a cascading effect on other readiness factors. For example, as reflected in Figure 3.0, each dimension may correlate with each other, and these findings may suggest there is a correlation between the financial resources, training, reward and recognition, and investment in essential resources (trainers, machines, and software) under top management support theme. The respondents highly suggested the top management should be eager to spend in LSS activities including appreciation programs, soft and hard technologies, training and contracting advisors to facilitate LSS implementation.

Two emerging readiness factors in the context of the food manufacturing industry. Respondents E3, E5, E7, E8, and E9 pointed out the appointing a change agent to lead the LSS readiness phase is particularly critical in the food business. The purpose is to ensure the LSS initiation is guided and have a smooth transition between the pre-implementation and implementation stages. The assignation of the LSS champion as the change agent was implemented at the implementation phase reflected the initiation of the LSS journey of the business [28].

Another newly identified readiness factor in the study is toplevel management awareness of the importance of LSS implementation. Top management should understand the demand for LSS implementation in their business and fully comprehend the reasons for embarking on the LSS. The top management was well-informed, primarily about the importance of a compulsory food safety programme in the food businesses depending on the type of food commodity. However, a brief LSS awareness session for the top management is suggested in the food sector to obtain the buy-in, commitment, and engagement in the LSS programme.

According to the vast majority of respondents, the ability to identify and maintain skillful human resources in LSS is essential for the successful implementation of LSS initiatives. Companies that initiate LSS with poor understanding and skills are deemed to fail to sustain the programme. The need for external experts is critical in educating theoretically and practically the team members because the training programme in class would be insufficient given the LSS project duration of six months, which would necessitate project consultation with the coach. According to E1and E2, it is common for the food companies to have the same staff becoming the internal expert for both, food safety and continuous improvement activities.

According to E3 and E8, the food industry has been characterized as a complex industry, that could be a factor in the effectiveness of LSS. The industry's complexity included industrial norms and standards, raw material types, procedures involved, and critical-to-quality performance monitoring. As respondents advocate updating machinery and software to examine the capability of measuring variations and performances of critical-to-quality characteristics, common concerns in production (e.g. long waiting duration when devices break down) must be considered.

Respondent E2 advocated that the LSS should be implemented within a realistic, feasible, and achievable time frame, with awards and recognition included in the continuous improvement programme. As a result, respondents recommended that relevant guidelines be developed as a handbook to direct the organization's implementation of the LSS. 
The involvement of qualified personnel in the quality management project is a significant indicator of preparedness at the LSS level. Identifying and training the right applicant would result in the addition of extrinsic value to the organization. However, several respondents emphasized that senior management has an ultimate say to choose the change agent/champion and let the decision of the project team's appropriate members to the champion. Typically, team members appointment happened at the implementation stage of the LSS. However, the respondents suggested that the existence of nurturing the top talent in the company should already have existed.

"It is critical to choose the suitable employees for the LSS belt training to see the return of investment of the training" (E6).

In the LSS implementation, having top talent is believed to have a better result, attracting more talent where it motivates the other employees to get involved [28].

Respondents E6, E7, E9, and E11 asserted that increasing LSS awareness would improve employees' willingness to adapt in favour of LSS implementation. It is agreed by the respondents that the employees will embrace better on the program when their understanding of the principal and advantage of LSS towards the business and themselves. LSS should be introduced as early as in tertiary education, where E5 stated that LSS can be embedded under related subjects in food bachelor degree program such as Operation Management, Quality Management and Supply Chain Management.

Additionally, several respondents indicated that specific tactics should focus on different projects. Implementing LSS should not be viewed as the answer for all production process issues. The importance of selecting the correct process and project contribute to the subsequent LSS adoption direction in the company. According to [3], project prioritization should be done in considering the best products in the business, contribution of the project to bottom-line saving and profit, contribution of the project to growth and impact of the project on the sustainability enhancement.

E9 warned that lack of LSS awareness would risk the success of the LSS adoption. In the food sector, interest in LSS can be nurtured through the other quality-related activities in the businesses, for instance, quality assurance and food safety activities. Another significant issue identified is the process for forming teams for CI activities, as they are considered as the main personnel accountable for quality improvement projects. Typically, food companies commonly will have a food safety team that adhered to both food safety and quality improvement issues.

Process management's fundamental notion is to understand quality criteria from the eyes of the customer. The guidelines and suggestions from LSS projects should be aligned with customer demands and the characteristics of each commodity in the food sector. E6 indicated that government assistance, such as establishing LSS awareness campaigns for the business, can be crucial in its readiness. The government can assist by engaging industry players through experience-sharing workshops and learning visits to LSS projects that have been successful as benchmarks and case studies.

\subsection{LSS CSFs in the food sector}

The findings indicated that 31 identified factor nodes contributed to the success of LSS implementation. The number of the codes was analyzed using Pareto analysis to determine their frequency and criticality under 80/20 rules. In [1], the author suggested that Pareto analysis helps classify "vital few" success factors from "trivial many," which focus on the factors to accentuate the desired goals.

Figure 3.0 shows that 17 CSFs were identified as the prioritized factors for the success of LSS implementation through $80 / 20$ rules. The food sector context identified training programmes as the most critical factors, followed by top management support, financial resources, communication structure employee involvement and as the top five main success factors for LSS implementation. Some of the CSFs are correlated and linked from the "unfreezing" stage to the "freezing stage" of LSS implementation. All of the LSS readiness factors in Figure 3.0, such as external factors (EF), employees involvement (EI), organizational culture (OC), management support and leadership (MSL) and project management (PM) are the common factor identified at the readiness and implementation phase of LSS.

Based on the prioritized CSFs, a causal mapping in Figure 4 developed based on the interview sessions showed that the potential of some of the factors have an impact on the emerging of other factors as the critical factor for the LSS program to be successful.

The respondents mentioned the training program has the most causal impact on successful LSS adoption, especially in this industry. Three distinct factors arose from the training: coaching and mentoring, LSS awareness and understanding level of LSS.

"Our LSS training programmes will include coaching and mentoring session as our company has hired in-house trainers to train the Green Belt/Black Belt programme for our employees."(E1)

"LSS basic training is crucial to create awareness among employees and their critical roles in LSS implementation." (E5)

"I would say continuous training for the employees is critical to increasing their understanding of the function and benefits of each LSS tool." (E12)

One of the most critical factors following the training programme was the support and commitment of senior management on LSS projects. Respondent E12 mentioned that the requirement of LSS project approval highly depends on the top management vision and buy-in of the project. 
"If there is new management, there must be massive support from the top to ensure they acknowledged and understand the benefits of current initiatives. When management is willing to invest in LSS projects, I would say they are supportive." (E7)

"I think that management support is influenced by their awareness on the advantages of LSS projects." (E10)

Another important factor to consider is the availability of financial resources and the budget allocation communicated by the top management to implement LSS initiatives. Another emerging factor that is relatable to the allocation of funding is the rewards and recognition. Respondents stated that their company allocates a budget for rewarding the employees and investment in cost-saving projects, which serve as a driving factor in making it a successful project. Another respondent responded on this issue:

"Having a strong financial capability to invest in systems, training, the hiring of trainers, and software is critical for any organization, in my opinion." (E2)

"LSS projects necessitate investment on the part of the management, particularly in terms of staff training and programme maintenance." (E6)
Another major component that contributed to the success of the LSS initiative in the food business was the participation of employees. In response to respondent R1, he stated that his company engages their employees by empowering them through hands-on training to provide the best exposure to them in the workplace. E7 stated that employee involvement led to awareness and an increased understanding of the LSS concept and benefits among those who worked for the company. Respondent E11 revealed that his company allows shop-floor employees to participate in decision-making, motivating and building trust among employees and management.

Medium of communication was identified as one of the most important CSFs that can be implemented to achieve a good result in the food business for successful LSS implementation. An effective communication program is essential, especially in convincing top management. He stated that top management roles in communicating the LSS strategic thinking to all departments are critical. Besides, it was to ensure the awareness of employees on LSS initiatives is under the same vision of the management. Other respondents stated that:

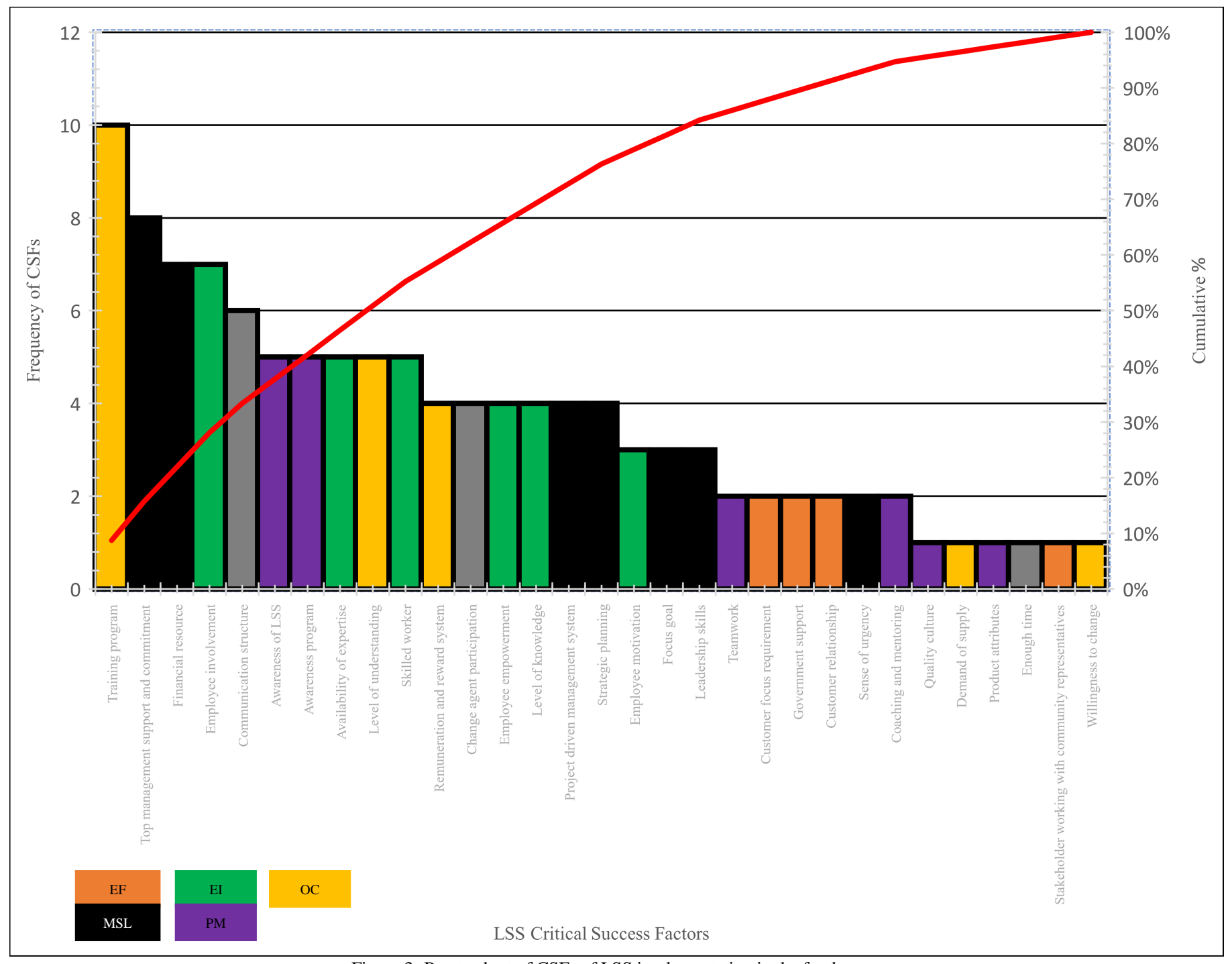

Figure 3: Pareto chart of CSFs of LSS implementation in the food sector 
"The acquisition is having a simple briefing to the shop floor to deliver the standard procedure of the LSS projects and ensuring that they are aware of how these projects will impact them is critical" (E8).

The Pareto chart in Figure 3 also revealed that the LSS enablers for the food sector mainly comprised of soft factors. The change process has an impact on any form of factors that could lead to the LSS implementation success in the food sector, including the "support from the government" and customer focus business. Some of the quotes being mentioned by the respondents:

"The government should provide help and support by rewarding those who complete successful LSS projects in a competition or by providing financial assistance to those who attend LSS training. Sources of coaches from other successful industries should be able to be an eye-opener" (E10)

"The LSS concept is driven by the ability to accrue the trust of the customer through value creation and variation reduction. The project should be tailored to the specific customer to ensure that it meets all of the customer requirements." (E1, E5).

\section{Discussions}

\subsection{Readiness factors and their causal relationship}

It was claimed that there is a necessity to explore critical and readiness factors for each sector because the nature and operations of various businesses may differ in terms of their factor, applicability, and value to the business [29]. The food sector's distinguishing traits, including the obligation to comply with strict food legislation rules, necessary cleaning of machinery and production sites, and the rapid changeover of various products, can impede the success and readiness of adopting LSS [2] and [30].

Venturing into LSS implementation necessitates high budget and continuous efforts, mandating strategic planning focused on the essential criteria during the pre-implementation stages to avoid overspending or underspending on CI operations [6, 11].

The findings revealed that management support and leadership, organizational culture readiness, employee involvement, process management, project management, and external interactions all impacted the preparedness of the LSS program. Figure 5 depicts the identified preparedness criteria to demonstrate the relationship between them.

\subsubsection{Management support and leadership (MSL)}

Management support and leadership was identified as the most critical factor at the pre-implementation phase. If any attempts at continuous improvement are to be made in a long time and with unwavering funding, this indicates a need for management support [11]. The organization's top management is capable of incorporating LSS as a business strategy for improving performance and business excellence. Implementing LSS demands significant capital expenditures and high commitments, demanding strategic planning to avoid cutting CI operations budget [6] and [16]. Management support implies that top management is taking action and developing plans to facilitate and steer the business's implementation of the LSS [1].

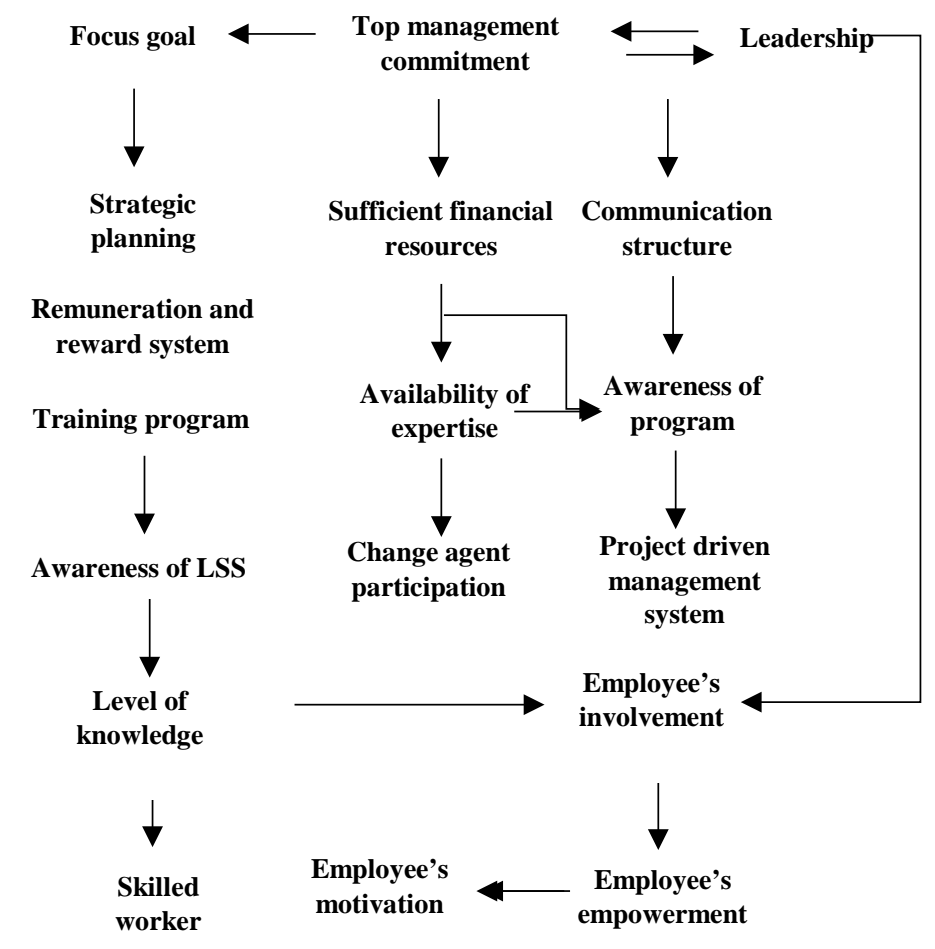

Figure 4: Causal diagram of the prioritized LSS CSFs in the food sector 


\subsubsection{Organizational culture readiness}

Following the interview, it was determined that in this industry, an organization's preparedness to adopt LSS relies on its organizational culture's willingness to adapt. According to a previous study, quality-driven culture should be promoted among employees in the organization. The foundation of success can be achieved with the corporate culture change [31] and [32] and [33]. Regular training enables the company to produce talented personnel with sufficient tools and techniques to be used by staff [32].

\subsubsection{Employee involvement}

Employee engagement is referring to the level of understanding of their roles within the company indicated the readiness of LSS activities. Employees who have adequate skills to apply the tools of LSS and an awareness of the principle of LSS are thought to be less reluctant to change. Operating as a team has been demonstrated to decrease the unwillingness towards the change, which validates the view articulated in the literature that management may appoint members and educate the team to tackle issues in process improvement [34]. By assigning employees to the problem-solving activity, the organization can help them feel more confident in their abilities. This would foster a sense of trust between top management and the employees.

\subsubsection{Project management}

The result shows that project management is a prominent LSS readiness factor as LSS is a project-based program. When administering the LSS project, prioritization should be made to deliver the most financial benefits to the firm [27], [32] and [35]. LSS project management entails determining the companywide level of understanding about LSS, which can inform the management on the company preparedness for LSS implementation [32]. Participation in the LSS awareness activities will increase the familiarity of the employees and minimize the unwillingness towards the change in the program's direction.

\subsubsection{Process management}

Considering the nature of the business, food businesses should consider integrating the LSS with customer relation activities. This will enable the voice of consumers will always be considered in the process and critical to quality attributes. The integrated components should be made as to the business's major priority for the future. Consumer requirements must be considered for the LSS projects to consider and increase the "consumer voice" while taking into account the particular features of the food sector. Gaining operational excellence is stated to be critical in the survival of a business [3]. Efficiency can be improved by identifying root causes, developing improvement solutions, and preventing them from occurring again [27], [34], [35], [36] and 37]. Aside from that, when a reliable system for measurement is accessible in the process, organizations are better prepared for LSS.

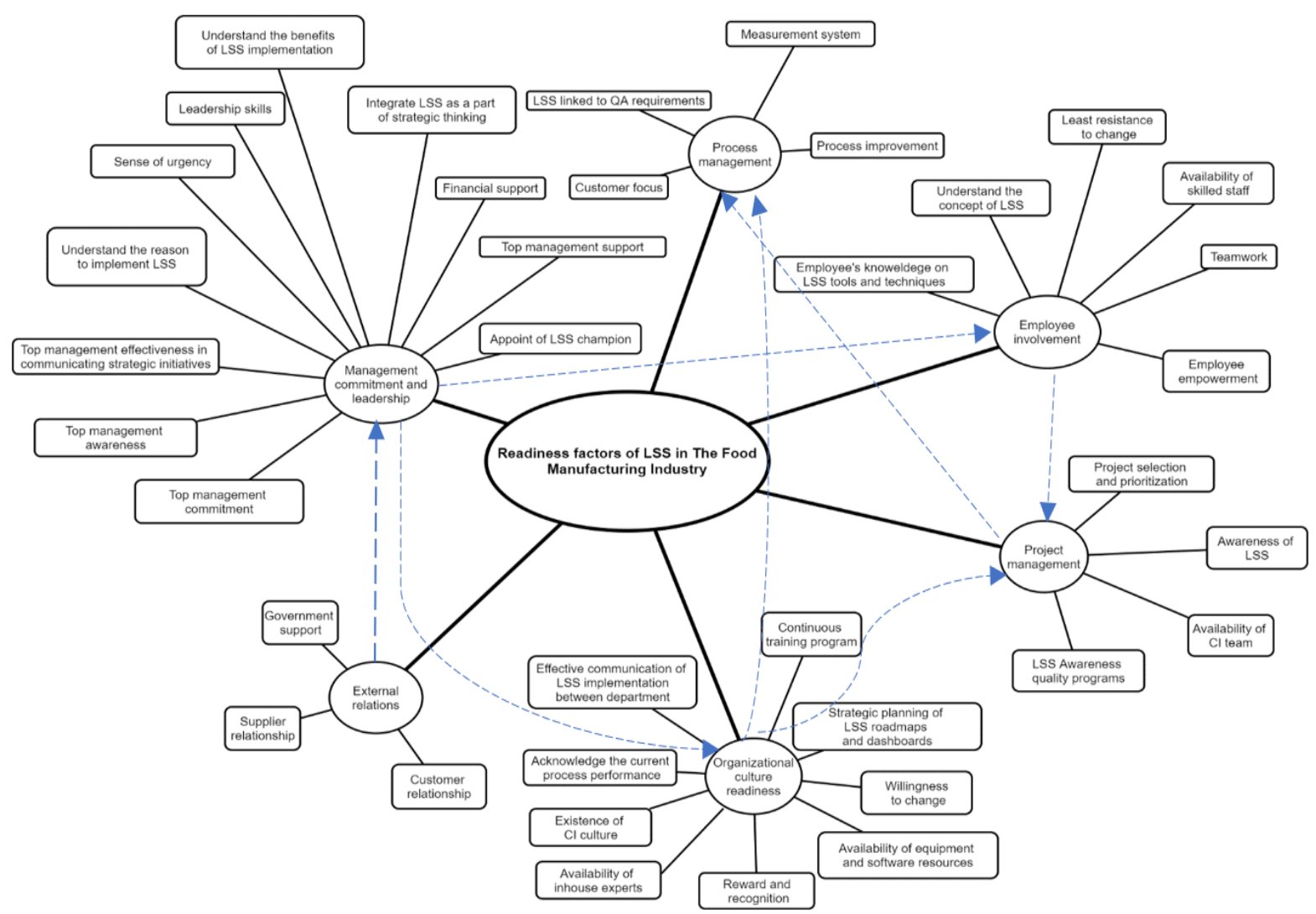

Figure 5: The conceptual LSS readiness factors in the food sector and its constructs. 


\subsubsection{External factors}

Most of the respondents discussed the importance of government support in initiating LSS in the food businesses. In the previous studies on LSS readiness, this factor is not commonly found. However, this component was identified as affecting the leanest implementation in the red meat business. The authorities play the policymaker's role and are responsible for strategizing effective adoption strategies [37]. However, cooperation between the external factors is defined as their events with their suppliers and customers [38]. Upon examination of the factors, it was discovered that management support has become the most vital determinant of LSS readiness. The management support entails the highest number of tasks in ensuring the preparedness of a food business to uptake LSS.

\section{Conclusions}

The implementation of a successful LSS can result in significant financial advantages for a company. However, most companies fail to implement LSS because they are pressured into doing so as part of a fad of business excellence approaches without taking the time to assess whether the organization is prepared to execute it successfully. The key research objective is discovering relevant factors that need to be assessed before investing in the LSS adoption customized for the food business, as well as the CSFs that must be considered throughout this process, as it is the linking phase following the readiness phase as according to Lewin's change theory.

According to the findings of this study, the emerging LSS readiness factors determined are management support and leadership, the readiness of organizational culture, employee involvement, process and project management, and finally external factors. The results show there is a proposition that the discovered factors for LSS implementation in this sector are causally related. The findings show $17 \mathrm{CSFs}$, where some of these factors are common factors under the readiness stage. In the food business, the most prevalent CSFs of the LSS are training, top management commitment and leadership, financial capacity, employee engagement, and communication.

There are two ways to look at the significance of this study. First, the determined LSS readiness factors provided a simple and easy approach as a decision-making tool to assist food sector practitioners in understanding their current practices, evaluating if their organizational environment supports LSS and finally deciding whether to invest in LSS Implementation. The managers also will be informed on the factors that are important in the preimplementation stage. Since some of the readiness themes were found will be an enabling factor in the implementation phase, the managers will be able to plan the implementation strategically. Whilst, for the food business that has implemented LSS, the result of this study opens the window to identify factors that require more attention to reach the targeted level of LSS readiness. Second, this paper extends to the limited body of knowledge about LSS implementation in the food sector and organizational readiness to change theory. Additionally, the findings of this study can be evaluated by comparing to those of similar studies conducted in various industries or countries, determining the impact of LSS readiness in different countries. Additionally, the findings of this study can be evaluated by comparing to the other similar studies conducted in various industries or countries, evaluating the impact of LSS readiness in different countries.

There were several limitations concerning the generalizability of this work, which provide the opportunity for future research. This study produced results that are described by the features of the interpretive type of study. While analyzing the data sets, it was found that hypothesis development must be built on a solid foundation, allowing for an empirical study to be conducted. Because the study used a small and focused sample, it was not possible to determine whether the findings had any external validity. Future research should consider that the result from grounded theory can be developed to hypothesis to be tested through quantitative study to establish a generalized LSS readiness factor with a larger sample size for the food sector. Future studies can also focus on the size of the company in the food production business such as big enterprise, medium or small. The identified factors can be used as the readiness measurement instrument in other industrial settings. Finally, the result of this study can be used as a vital theory for the construction of an LSS readiness diagnostic tool for the food sector.

\section{Conflict of Interest}

The authors declare no conflict of interest.

\section{Acknowledgement}

This work is supported by the Universiti Putra Malaysia under research grant Putra Young Initiative (IPM/2017/9552400) and Malaysia Ministry of Education (MOE) for providing research grant under Fundamental Research Grant Scheme (FRGS/1/2018/TK03/UPM/02/7).

\section{References}

[1] S.A.H. Lim, J. Antony, "Statistical process control readiness in the food sector: Development of a self- assessment tool," Trends in Food Science and Technology, 58, 133-139, 2016, doi:10.1016/j.tifs.2016.10.025.

[2] M. Dora, X. Gellynck. "Lean six sigma implementations in a food processing SME: A case study," Quality and Reliability Engineering International, 31, 1151-1159, 2015, doi:10.1002/qre.1852

[3] V. R. Sreedharan, R. Raju, M. V. Sunder, J. Antony, "Assessment of lean six sigma readiness (LESIRE) for manufacturing industries using fuzzy logic," International Journal of Quality and Reliability Management, 36(2), 137161, 2019, doi:1108/IJQRM-09-2017-0181.

[4] L. B. M. Costa, M. G. Filho, L. D. Fredendall, F. J. Gómez Paredes, "Lean, six sigma and lean six sigma in the food sector: A systematic literature review," Trends in Food Science and Technology, 82, 122- 133, 2018, doi:10.1016/j. tifs.2018.10.002.

[5] L. Marrucci, M. Marchi, T. Daddi, "Improving the carbon footprint of food and packaging waste management in a supermarket of the Italian retail sector," Waste Management, 105, 594-603, 2020, doi:10.1016/j.wasman.2020.03.002.

[6] L.B.M. Costa, M. G. Filho, L. D. Fredendall , G.M.D Ganga, "The effect of lean six sigma practices on food sector performance: Implications of the Sector's experience and typical characteristics," Food Control, 112, 2020, doi:10.1016/j.foodcont.2020.107110

[7] J. A. Garza-reyes, I. E. Betsis, V. Kumar, M.A.R. Al-Shboul, "Lean readiness-the case of European pharmaceutical manufacturing industry," 
International Journal of Productivity and Performance Management, 67(1), 20-44, 2018, doi: 10.1108/IJPpm-04-2016-0083

[8] B.V. Chowdary, D. George, "Improvement of manufacturing operations at a pharmaceutical company: a lean manufacturing approach," Journal of Manufacturing Technology Management, 23 (1), 56-75, 2012, doi: 10.1108/17410381211196285.

[9] A. A. Armenakis, S. G. Harris, K. Mossholder, "Creating readiness for organizational change," Human Relations, 46, 681-703, 1993,doi:10.1177/001872679304600601.

[10] Z. Radnor, 2011. "Implementing lean in health care: making the link between the approach, readiness and sustainability," International Journal of Industrial Engineering and Management, 2(1), 1-12, 2011, doi: 10.1016/j.socscimed.2011.01.011.

[11] J. Antony, "Readiness factors for the lean six sigma journey in the higher education sector," International Journal of Productivity and Performance Management, 63(2), 257-264, 2014, doi:10.1108/IJPPM-04-2013-0077

[12] C.Andrea, and M. Kumar. "Lean Six Sigma and Industry 4.0 integration for Operational Excellence: evidence from Italian manufacturing companies." Production Planning \& Control, 32(13), 1084-1101, 2020, doi:10.1080/09537287.2020.1784485

[13] E.H. Jacobson, "The effect of changing industrial methods and automation on personnel," Paper presented at the Symposium on Preventive and Social Psychology, Washington, DC, 1957.

[14] S. Al-Balushi, P.J. Sohal, P.J. Singh, A. Al Hajri, Y.M. Al Farsi,R, Al Abri, "Readiness factors for lean implementation in healthcare settings - a literature review," Journal of Health Organization and Management, 28(2), 135-153, 2014, doi: 10.1108/JHOM-04-2013-0083.

[15] B.J. Weiner, "A theory of organizational readiness to change," Implementation Science, 4(1), 67, 2009, doi: \10.1186/1748-5908-4-67.

[16] E. Drohomeretski, S. E. G. da Costa, E. P. de Lima, P. A. Garbuio, "Lean, six sigma and lean six sigma: An analysis based on operations strategy," International Journal of Production Research, 52(3), 804-824, 2014, doi:10.1080/00207543.2013.842015.

[17] C. Robson, K. McCartan, Real world research (4th ed.), John Wiley \& Sons, 2006.

[18] M. B. Miles, A. M. Huberman, Qualitative data analysis: An expanded sourcebook., Sage Publications, 1994

[19] M. Q. Patton, Qualitative research and evaluation methods, Thousand Oaks, Sage, 2002.

[20] MG Filho, GMD. Ganga, A. Gunasekaran, "Lean manufacturing in Brazilian small and medium enterprises: Implementation and effect on performance," International Journal of Production Research, 7543, 1-23, 2016, doi: 10.1080/00207543.2016.1201606.

[21] M. Dikko, "Establishing construct validity and reliability: Pilot testing of a qualitative interview for research in takaful (islamic insurance)," The Qualitative Report, 21, (3), 521- 528, 2016, doi: 10.46743/21603715/2016.2243.

[22] R. Bogdan, S.K. Biklen, Qualitative research for education: An introduction to theories and methods, Pearson A \& B, 2007.

[23] E. Guba, "Criteria for assessing the trustworthiness of naturalistic inquiries," Educational Technology Research and Development, 29(2), 75-91, 1981, doi::

[24] M.A. Abernethy, M. Horne, A.M. Lillis, M.A. Mallina, F.H. Selto, "A multimethod approach to building causal performance maps from expert knowledge," Management Accounting Research, 16(2), 135-155, 2005, doi: 10.1016/j.mar.2005.03.003.

[25] I. Pyrko, V. Dörfler, "Using causal mapping in the analysis of semistructured interviews," In Academy of Management Proceedings , 2018(1), 2018, doi: 10.5465/ambpp.2018.14348abstract.

[26] A. J. Scavarda, T. Bouzdine-Chameeva, S. M. Goldstein, J.M. Hays, A. V. Hill, "A methodology for constructing collective causal maps," Decision Sciences, 37(2), 263-283, 2006, doi: 10.1111/j.1540-5915.2006.00124.x.

[27] K. Jayaraman, T. Leam Kee, K. Lin Soh, "The perceptions and perspectives of lean six sigma (LSS) practitioners," The TQM Journal, 24(5), 433-446, 2012, doi: 10.1108/17542731211261584.

[28] V. F., Vallejo, J. Antony, Douglas, J. A., Alexander, P., \& Sony, M. (2020). Development of a roadmap for Lean Six Sigma implementation and sustainability in a Scottish packing company. The TQM Journal.

[29] J. Rockart, "Chief executives define their own data needs," Harvard Business Review, 57(2), 1979.

[30] A. Panwar, B.P. Nepal, R. Jain, A. P. S. Rathore, "On the adoption of lean manufacturing principles in process industries," Production Planning \& Control, 26(7), 564-587, 2015, doi: 10.1180/09537287.2014.936532.

[31] A. Gurumurthy, P. Mazumdar, S. Muthusubramanian, "Graph theoretic approach for analyzing the readiness of an organization for adapting lean thinking: a case study," International Journal of Organizational Analysis, 21(3), 96-427, 2013, doi:10.1108/ IJOA-04-2013-0652.

[32] Y. Lagrosen, R. Chebl, M. Rios Tuesta, "Organizational learning and six sigma deployment readiness evaluation: A case study," International Journal of Lean Six Sigma, 2(1), 23-40, 2011, doi: 10.1108/20401461111119431.

[33] SC. Cross, "Lean cuisine." Industrial Engineer, 41(1), 46-47, 2009

[34] P.B. Keliji, B.S.D Abadi, M. Abedini, "Investigating readiness in the Iranian steel industry through six sigma combined with fuzzy delphi and fuzzy DANP," Decision Science Letters, 7, 465-480, 2018, doi: 10.5267/j.dsl.2018.1.001.

[35] M. N. Mishra, "Identify critical success factors to implement integrated green and lean six sigma," International Journal of Lean Six Sigma, 2018, doi:10.1108/IJLSS-07-2017-0076.

[36] T. Y. Lee, W. K. Wong, K. W. Yeung, "Developing a readiness selfassessment model (RSM) for six sigma for China enterprises," International Journal of Quality and Reliability Management, . 28(2),169-194, 2011, doi: 10.1108/02656711111101746.

[37] A. Cox, D. Chicksand, M. Palmer, "Stairways to heaven or treadmills to oblivion?: Creating sustainable strategies in red meat supply chains," British Food Journal, 109, 2007, doi:10.1108/00070700710780689

[38] C. A. Moya, D. Galvez, L. Muller, M. Camargo, "A new framework to support lean six sigma deployment in SMEs," International Journal of Lean Six Sigma, 10(1), 58-80, 2019, doi:10.1108/IJLSS-01-2018-0001. 